\title{
CONTANDO HISTÓRIAS E APRENDENDO FÍSICA: UMA EXPERIÊNCIA COM ALUNOS CEGOS E COM BAIXA VISÃO*
}

\author{
Sofia Castro Hallais ${ }^{1}$ \\ Angélica Ferreira Bêta Monteiro ${ }^{2}$ \\ Bernardo Copello Alves ${ }^{3}$ \\ Maria da Conceição de Almeida Barbosa-Lima ${ }^{4}$
}

\section{INTRODUÇÃO}

Neste artigo relatamos uma experiência de ensinar conceitos de Óptica a partir de uma história infantil para alunos do Ensino Fundamental ( $3^{\circ}$ ao $5^{\circ}$ ano), matriculados em um instituto especializado para alunos com deficiência visual (DV).

Tendo como base o referencial histórico-cultural da Teoria da Atividade (TA) proposta por Leontiev, onde o conhecimento é considerado uma autoconstrução à medida que o sujeito adquire dados oferecidos pelos outros ou pelos fenômenos do meio natural e social, no qual reorganiza e reelabora segundo sua capacidade, suas motivações e interesses.

Como o público são crianças, utilizamos a contação de história para despertar o interesse e para enriquecer ainda mais esta estratégia. Nos apoiamos na metodologia apresentada na didática multissensorial proposta por Soler, considerada um método pedagógico para o ensino e aprendizagem das ciências experimentais e da natureza, que propõe

\footnotetext{
${ }^{*}$ DOI - 10.29388/978-65-86678-08-6-0-f.27-36

${ }^{1}$ Instituto Oswaldo Cruz, Fiocruz, E-mail: sofiahallais@gmail.com

${ }^{2}$ Instituto Oswaldo Cruz, Fiocruz / Instituto Benjamin Constant,

E-mail: afbm2007@yahoo.com.br

${ }^{3}$ Instituto Oswaldo Cruz, E-mail: Fiocruz, E-mail: bernardocopelloalves@gmail.com

${ }^{4}$ Instituto Oswaldo Cruz / Universidade do Estado do Rio de Janeiro,

E-mail: mcablima@uol.com.br.
} 
o uso de todos os sentidos (tato, paladar, audição e olfato) e não apenas a visão para captar informação do meio que nos rodeia.

A seguir, abordaremos com mais detalhes tais teorias, os aspectos metodológicos da atividade realizada e a análise dos resultados.

\section{REFERENCIAL TEÓRICO}

\subsection{Teoria Histórico-social ou Teoria da Atividade}

Neste trabalho utilizamos a Teoria da Atividade desenvolvida por Alexei Nikolaevich Leontiev como referencial teórico. Tal teoria é baseada no contexto Histórico-social, destacando uma relação entre homem e sociedade, e a mediação por instrumento dessa relação.

[...] Para Leontiev, o papel da atividade prática dos sujeitos, as relações práticas com o mundo eram mais importantes do que os processos de comunicação, pois, para ele, a comunicação se dá na atividade prática (NÚÑEZ, 2009, p. 63).

Leontiev definiu o conceito de atividade como sendo responsável pelo desenvolvimento das funções psíquicas do aluno, no qual o desenvolvimento decorre das atividades que ele realiza.

$\mathrm{O}$ homem se desenvolve por meio da atividade que exerce. Assim, o desenvolvimento das funções psíquicas decorre de um processo de apropriação, que transforma a atividade externa em atividade interna. Dessa forma, o processo de apropriação do conhecimento acontece no convívio social. Portanto, o homem se apropria não só de mecanismos materiais, mas também de todo um sistema de significações que foram formados historicamente. (LEONTIEV, 1978).

Para o autor, a atividade é um sistema estruturado, com ações que gerarão transformações internas, no qual essas operações são o caminho para a internalização do conceito, que originará diversos atos mentais como o pensamento que é mediado pela linguagem. 
É importante não confundirmos a atividade para Leontiev com ação ou prática. Para poder ser denominada de atividade, é fundamental ter três elementos: a necessidade, o objeto e o motivo, onde todos necessariamente precisam ter relação com o meio em que o sujeito está inserido. Sendo todos relacionados com o meio em que o sujeito está inserido. Para isso é necessário ter um instrumento que direciona essa atividade, possibilitando ao aluno relacionar-se com os objetos e também com outros alunos, pois é no instrumento que se cristalizam os procedimentos e operações.

A necessidade que o autor aborda é o que regula e orienta a atividade concreta do sujeito em seu meio objetivo, porém o meio externo também pode criar as necessidades dos indivíduos, levando-os a agir.

Segundo Leontiev (1978), “[a]s ações que realizam atividade são despertadas por seu motivo, mas estão direcionadas para um objetivo". Os fins podem ser os mesmos, mas as condições em que se dão podem ser modificadas, alterando a composição da ação.

Em contato direto com a realidade objetiva, a atividade se transforma, se enriquece e neste enriquecimento se cristaliza no produto, assim a atividade realizada é mais rica, mais verdadeira do que a consciência que a prevê, mas para que esse produto se apresente ao sujeito de forma cognitiva, deve ocorrer uma transformação, que se opera mediante ao funcionamento da linguagem.

\subsection{Didática Multissensorial de Soler}

A didática multissensorial definida por Soler (1999, p. 45) como um método pedagógico para o ensino e aprendizagem que utiliza todos os sentidos humanos; o tato, a audição, a visão, o paladar e o olfato para captar informações do meio que nos rodeia.

Soler (1999) classifica os sentidos como sintéticos e analíticos. Os sentidos sintéticos são os que percebem os fenômenos do geral para o particular (processo indutivo), como a visão, a audição, o olfato 
e o paladar. $\mathrm{O}$ tato, por sua vez, é um sentido analítico que percebe o fenômeno do particular para o geral (processo indutivo). A combinação desses processos é uma produção da aprendizagem.

Para uma pessoa com DV, o olfato, o paladar, o tato e a audição são ferramentas que funcionam como centros geradores de uma nova percepção, contribuindo para a formação de conceitos com significados mais complexos para este indivíduo.

\section{METODOLOGIA}

Foram utilizados dois encontros da oficina "Aprendendo Ciências de um jeito diferente" oferecida por um instituto especializado em DV. A atividade aconteceu uma vez na semana, à tarde, na forma de atividade complementar e cada encontro teve a duração de noventa minutos. A turma foi composta por sete alunos com DV, sendo quatro cegos e três com baixa-visão.

Os alunos matriculados na oficina tinham entre oito e doze anos de idade e cursavam do segundo ao quinto ano do Ensino Fundamental. Na primeira parte da atividade contamos a história "As nervuras das verduras" (LIMA; SOUZA, 2019) que relata a experiência de uma menina cega que queria aprender sobre as cores e sua professora a ensina a partir dos alimentos, mostrando as texturas, nervuras, cheiros e sabores.

$\mathrm{Na}$ segunda parte da atividade, estimulando ainda mais a atenção, percepção e memória dos alunos, estes experimentaram frutas e verduras, analisando o formato, a textura e o cheiro. Por fim, cada aluno falou sobre a experiência vivenciada, fazendo associações e comparações com a história contada. Cada momento da atividade foi gravado e filmado, onde posteriormente assistimos e transcrevemos os trechos mais significativos para o trabalho. 


\section{ANÁLISE E RESULTADOS}

A seguir transcrevemos as falas mais significativas que corroboram com as teorias apresentadas inicialmente neste trabalho. Utilizamos os números de 1 ao 4 para preservar e manter a integridade dos alunos.

Professora: Vocês têm curiosidade de saber sobre as cores?

Todos: Sim.

Professora: Alguém consegue ver as cores?

Aluno 1: Eu não consigo ver nada.

Aluno 2: Eu acho que consigo ver um pouquinho.

Aluno 3: Não.

TÓPICO 1: AS FRUTAS

Professora: Vocês conhecem as frutas que estão na mesa: laranja, abacaxi e tomate?

Todos: Sim.

Professora: Qual é doce, ácida ou azeda? Começando pelo abacaxi.

Aluno 1: Ácido.

Aluno 2: Doce

Professora: Tomate?

Aluno 3: Doce.

Aluno 1: Não sei.

Professora: Maçã?

Todos: Doce.

Professora: Laranja?

Todos: Ácida.

Professora: Qual a textura do tomate?

Todos: Liso.

Professora: Qual a textura da laranja?

Aluno 2: Mais ou menos liso.

Aluno 3: A casca é mais grossa. 
Professora: Qual a textura do abacaxi?

Todos: Têm espinho.

\section{TÓPICO 2: AS VERDURAS}

Professora: Qual a textura do repolho?

Aluno 1: Liso?!

Aluno 2: Tem ondinha.

Professora: Essas ondinhas se chamam?

Todos: Nervuras.

Professora: Temos três verduras na mesa, sabem quais são?

Aluno 2: Repolho, alface e couve.

\section{TÓPICO 3: AS CORES}

Professora: Agora, vocês acham que o sabor, a textura tem haver com a cor?

Aluno 1: Depende.

Aluno 2: Não sei.

Professora: As cores verdes, por exemplo, como a alface?

Aluno 4: Acho que não tem muito gosto.

Professora: Por isso a alface tem a cor verde claro devido o seu sabor.

\section{ANÁLISE:}

Percebemos que todos os alunos conheciam as frutas e as verduras apresentadas na história. E durante o diálogo identificaram as texturas, tendo pequenas dificuldades em diferenciar o doce, o ácido e amargo e a princípio as cores das frutas. Depois que exploramos mais o sabor e falamos as cores, eles próprios começaram a perceber a semelhança, inclusive ressaltando sobre as nervuras, parte que relacionaram com a explicação da história. Ao final, todos conseguiram compreender as cores pelos sentidos que usaram para identificar as frutas $\mathrm{e}$ verduras.

Tal atividade ressalta a importância quando Leontiev (1978a, b) 
afirma que é necessário um conjunto de ações para concretizar o objetivo para que o aluno consiga internalizar o conceito de cores, no caso. E para que os alunos conseguissem compreender, relacionando com a história contada, utilizamos os sentidos humanos como canais de comunicação, o que corrobora com a didática multissensorial de Soler (1999) e contribui para a formação de conceitos com significados mais complexos.

Figura 1. Alunos reconhecendo frutas e verduras pelo tato e olfato
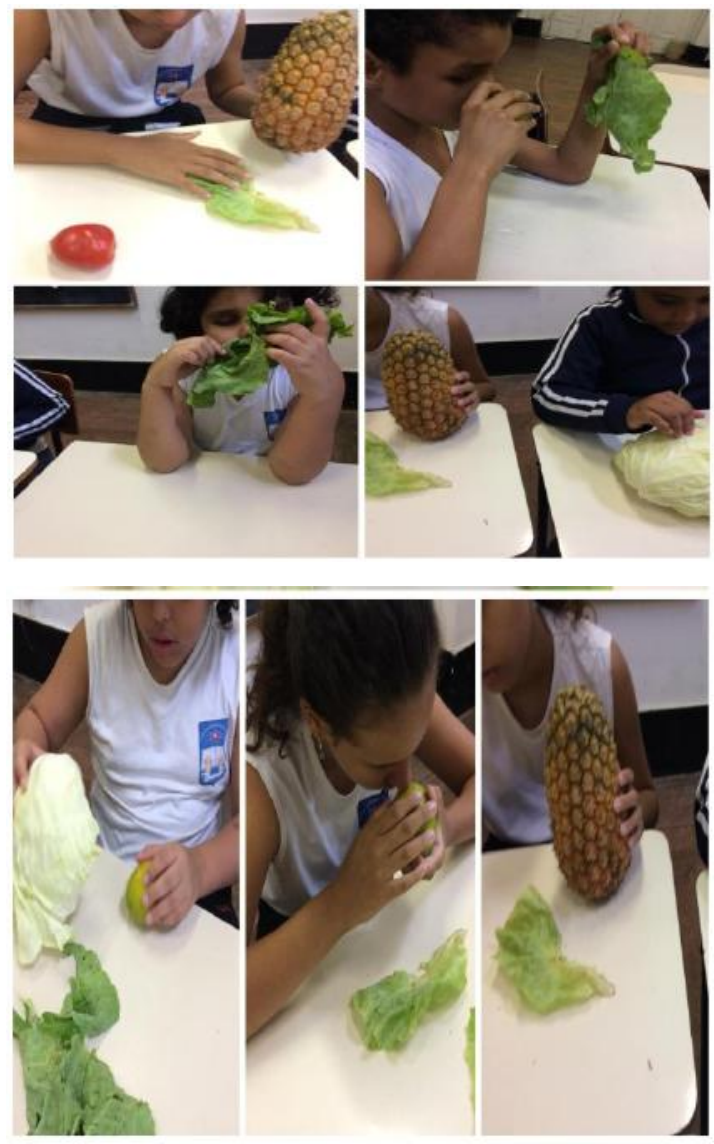

Fonte: os autores 


\section{CONSIDERAÇÕES FINAIS}

Atualmente, o ensino na sala de aula está pautado em ações, e não, em atividades. Isso fica mais claro, quando percebemos que o objetivo do aluno não é o mesmo da atividade. Cabe ao professor estar mais atento quanto às necessidades, dificuldades e aquilo que seus alunos já sabem sobre determinado conteúdo, a fim de construir um sistema de operações voltado para uma ação que os motive a aprender.

Para o aluno, a aprendizagem é:

[...] entendida como construção de conhecimento, pressupõe entender tanto na dimensão como produto quanto sua dimensão como processo, isto é, o caminho pelo qual os alunos elaboram pessoalmente os conhecimentos (COLL et al., 1996, p. 88).

Através deste trabalho relacionamos a teoria com a prática, que a partir de uma contação de história e da experiência com frutas e verduras os alunos exploraram conceitos científicos e conseguiram relacionar a cor do alimento ao sabor.

É fundamental que o professor perceba a importância da aprendizagem, pois ela irá norteá-lo no ato de ensinar. Para que o aluno compreenda algo, seja um objeto da realidade ou um conteúdo, é preciso ir além de uma resolução de um exercício, é necessário buscar promover a concepção de um conhecimento científico em que o indivíduo perceba e consiga identificar tal conceito em outras situações cotidianas.

\section{REFERÊNCIAS}

COLL, C. et al. O Construtivismo na sala de aula. São Paulo: Ática, 1996, p. 88

LIMA, Conceição Barbosa; SOUZA, Eduardo. Histórias para ler e aprender. São Paulo: LF, 2019. 92 p. 
LEONTIEV, A.N. Actividad, conciencia y personalidad. Buenos Aires: Ediciones Ciencias Del Hombre, 1978a.

. O desenvolvimento do psiquismo (M. D.Duarte, Trad.). Lisboa: Livros Horizonte, 1978 b.

NÚÑEZ, I. B. Vygotsky, Leontiev e Galperin: formação de conceitos e princípios didáticos. Brasília: Liber Livro, 2009,p. 63

SOLER, m. A. (1999) Didáctica multissensorial de las ciencias: un nuevo método para alumnos ciegos, deficientes visuales, y también sin problemas de visión. Barcelona: Ediciones Paidós Ibérica. 
